\title{
Mineralização aurífera em veios de pirita maciça na Serra da Paciência - Bahia - tipologia distinta dos conglomerados com Au-U do Grupo Jacobina
}

Daniel Augusto de Miranda (daniel.miranda@cprm.gov.br)

Fabrício Pereira dos Santos (fabricio.santos@cprm.gov.br)

Carolina Reis (carolina@cprm.gov.br)

Rita Cunha Leal Menezes de Oliveira (rita.oliveira@cprm.gov.br)

CPRM - Serviço Geológico do Brasil, SUREG-SA - Superintendência Regional de Salvador

\begin{abstract}
Gold mineralization that differs from the classic conglomerate-hosted Au-U mineralization from Serra da Jacobina was found at Serra da Paciência, $6 \mathrm{~km}$ north-northwest of Pindobaçu town, Bahia State. The mineralization occurs 100 meters south of garimpo Mina Velha and consists of a $40 \mathrm{~cm}$-thick gold-bearing vein of massive pyrite hosted in a chloritite (metamorphosed ultramafic dike), which intrudes quartzites of the Cruz das Almas Formation (Jacobina Group). The chloritite has N-S direction, thickness between 1,5 and $2 \mathrm{~m}$ and is affected by a reverse fault of 095/63 attitude. Samples of massive pyrite returned Au grades of 336 and 385 $\mathrm{ppb}$. At the garimpo Mina Velha gold mineralization is related to pyrite-bearing quartz veins hosted by chloritite affected by the same reverse fault. Gold values in samples from Mina Velha range from $239 \mathrm{ppb}$, in the chloritite, to $22,660 \mathrm{ppb}$, in the pyrite-bearing quartz vein. The gold occurrence related to massive pyrite vein reveals to be a prospective alternative different from the conglomerate-hosted $\mathrm{Au}-\mathrm{U}$ of the Jacobina Group.
\end{abstract}

Keywords: Serra de Jacobina. Hydrothermalism. Gold.

Palavras-chave: Serra de Jacobina. Hidrotermalismo. Ouro.

\section{INTRODUÇÃO}

Os conglomerados com Au-U da Serra de Jacobina são mundialmente conhecidos pelas características que permitem correlaciona-los a depósitos do tipo paleoplacer como Witwatersrand (BATEMAN, 1958). Apesar disso, outras diversas ocorrências auríferas hidrotermais associadas a quartzitos, rochas ultramáficas e máficas são exploradas na forma de garimpos e ocorrem ao longo de toda a Serra de Jacobina (TEIXEIRA et al., 2001; PEARSON et al., 2005).

$O$ presente estudo pretende complementar a descrição das ocorrências auríferas acrescentando uma tipologia de mineralização aurífera associada a veios de pirita maciça hospedados em rochas ultramáficas.

Embora tais mineralizações sejam conhecidas pelos trabalhos exploratórios de empresas da região, não foram encontrados estudos específicos com foco na descrição desta tipologia.

Este estudo decorre do Projeto Integração Geológica e Avaliação do Potencial Metalogenético da Serra de Jacobina e do Greenstone Belt de Mundo Novo (ARIM Jacobina), ligado ao programa Áreas de Relevante Interesse Mineral (ARIM) da DGM/CPRM.

\section{CONTEXTO GEOTECTÔNICO E GEOLOGIA RE- GIONAL}

A Serra de Jacobina está situada na borda leste do Bloco Gavião, Cráton do São Francisco (Figura 1). Compreende uma estrutura com 220 quilômetros de extensão, alinhada na direção norte-sul, resultante da amalgamação das bacias metassedimentares representadas pelo Grupo Jacobina e Complexo Saúde, e rochas metavulcanossedimentares do Greenstone 
Belt de Mundo Novo. Estas unidades estão depositadas sobre embasamento do tipo TTG e são intrudidas por leucogranitos diversos (LEITE; MARINHO, 2012).

Mascarenhas et al. (1998) apresentam estudo comparativo das diversas colunas estratigráficas propostas para a bacia paleoproterozoica representada pelo Grupo Jacobina e propõe uma subdivisão nas formações Serra do Córrego, Rio do Ouro, Cruz das Almas, Serra do Meio e Serra da Paciência. Estas unidades apresentam da base para o topo uma intercalação entre quartzitos e conglomerados, quartzitos com marcas onduladas e estratificações cruzadas bidirecionais e quartzitos com intercalações de andaluzita xistos. Mascarenhas et al. (1994) e Teles et al. (2015) interpretam a sequência como característica de um modelo de bacia do tipo rift, enquanto Ledru et al. (1997) sugerem modelo de antepaís.

O Grupo Jacobina possui intercalações de rochas ultramáficas cloritizadas, alinhadas segundo a direção N-S, cujo posicionamento estratigráfico é controverso (TEIXEIRA et al., 2001). Couto et al. (1978) descrevem estes litotipos como intrusivos ao Grupo Jacobina e associam ao Complexo Itapicuru. Mascarenhas et al. (1998) correlacionam estas rochas ao Domínio Máfico/Ultramáfico do Greenstone Belt de Mundo Novo e afirmam que tratam-se de lascas tectônicas imbricadas no Grupo Jacobina.

Diques máficos a intermediários, tarditectônicos, com direção geral E-W, intrudem as rochas metassedimentares do Grupo Jacobina e as intercalações ultramáficas de direção N-S. São compostos de metagabros e metadioritos de idade indefinida. (TEIXEIRA et al., 2001; PEARSON et al.; 2005).

\section{TIPOLOGIA DAS MINERALIZAÇÕES AURÍFERAS}

Existem diversos modelos sobre a origem das mineralizações de Au-U associadas aos conglomerados da Formação Serra do Córrego. Bateman (1958) advoga uma origem sedimentar (paleoplacer) enquanto Gross (1968) indica uma origem sedimentar modificada (modified paleoplacer). Já White (1961) e Cox (1967) defendem uma origem epigenética da mineralização. Milesi et al. (2002) apresentam o modelo "hydrothermal shear-reservoir" em que admitem um enriquecimento aurífero epigenético sem destacar uma origem primária sedimentar associada aos conglomerados.

Além do ouro associado aos conglomerados da Formação Serra do Córrego ocorrem pelo menos outros quatro tipos de mineralizações auríferas na Serra de Jacobina associadas: (i) ao Grupo Jacobina (formações Rio do Ouro e Cruz das Almas); (ii) às rochas ultramáficas de direção N-S; (iii) aos diques máficos a intermediários; (iv) ao Greenstone Belt de Mundo Novo. Teixeira et al.(2001) e Pearson et al. (2005) classificam estas tipologias em função da sua rocha hospedeira. Baseados na observação do controle estrutural de corpos mineralizados com alteração hidrotermal e na ocorrência de ouro nestas diferentes unidades os autores propõe um modelo de mineralização epigenética para estas tipologias.

A tipologia apresentada neste trabalho está associada às rochas ultramáficas de direção $\mathrm{N}-\mathrm{S}$ e não havia sido descrita nos trabalhos anteriores.

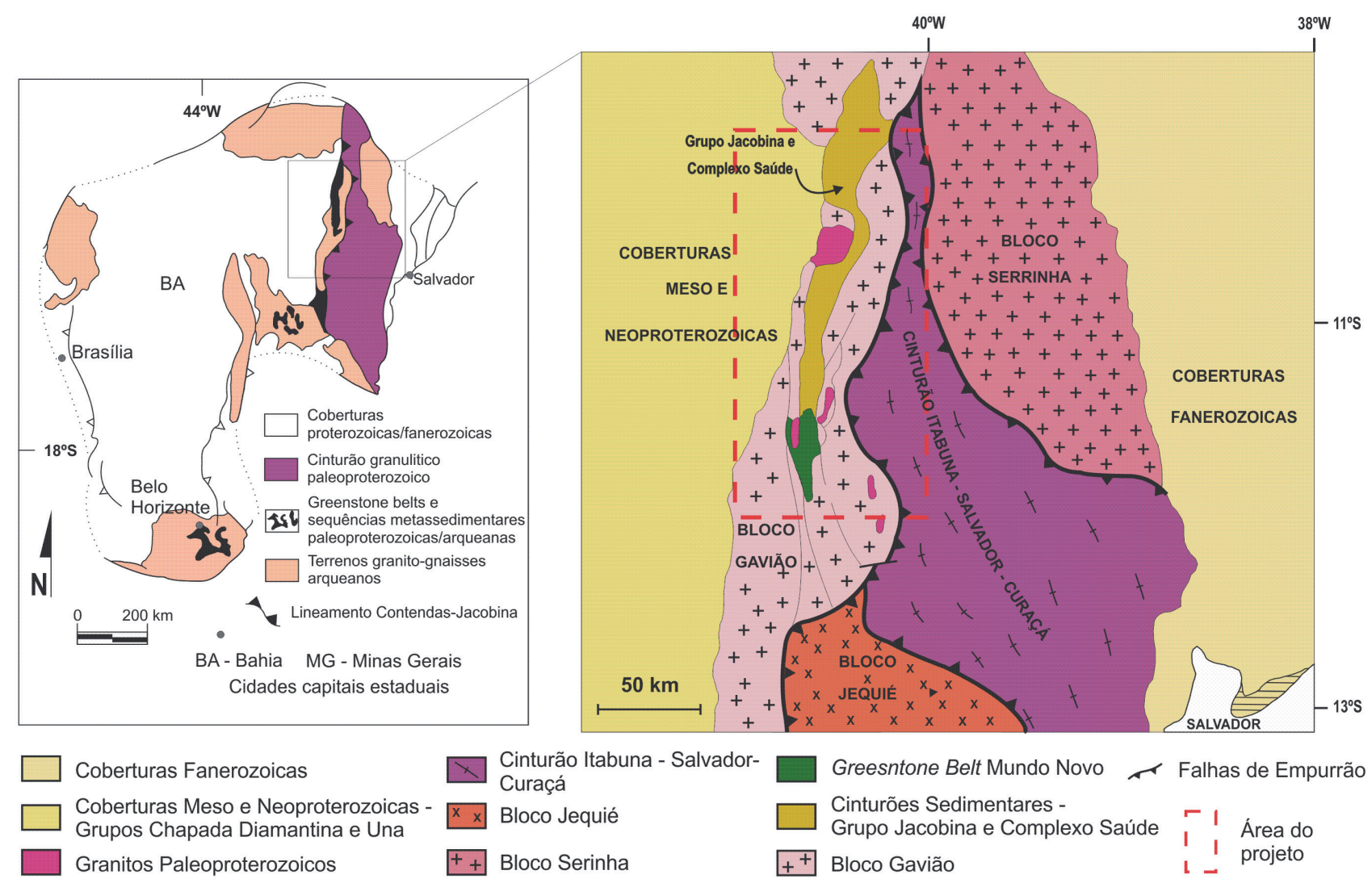

Figura 1 - Contexto geotectônico da Serra de Jacobina. Modificado de Leite e Marinho (2012). 


\section{DESCRIÇÃO DA OCORRÊNCIA}

A ocorrência constatada está situada nas coordenadas UTM N 8.817.880, E 349.298 com elevação 781 metros (Zona 24L, datum SIRGAS 2000), nas imediações do garimpo Mina Velha, na Serra da Paciência, aproximadamente seis quilômetros a NNW da cidade de Pindobaçu, Bahia (Figura 2).

Na Serra da Paciência predominam quartzitos com estratificação cruzada acanalada, bidirecional e marcas onduladas da Formação Cruz das Almas, denominação utilizada no presente trabalho, definida por Couto et al. (1978) e adotada também por Teixeira et al. (2001).

Pearson et al. (2005) referem-se a estes quartzitos como Formação Serra da Paciência. Esta é estruturada segundo uma série de antiformes e sinformes abertos, com eixos de direção geral NNE-SSW e caimento em torno de $10^{\circ}$ para NNE. O mergulho do plano axial é subvertical com traço de direção NNE-SSW.

A Figura 3 apresenta o esboço geológico da região do garimpo Mina Velha e a localização da ocorrência de pirita maciça aurífera.

No garimpo Mina Velha a mineralização está hospedada em uma falha reversa oblíqua (Figura 4A).

$\mathrm{O}$ minério lavrado pelos garimpeiros é o cloritito intemperizado encaixado no plano de falha ( $\mathrm{Fi}$ gura 4B). Este cloritito é interpretado como um dique de origem ultramáfica e hospeda veios de quartzo intensamente oxidados. Em lâmina delgada observa-se que a matriz é composta essencialmente por clorita. A rocha está tectonizada, com a presença de quartzo fitado e grãos de pirita orientados ao longo da foliação (Figuras 5A e 5B). Em outras porções da Serra de Jacobina, associados a estes clorititos ocorrem serpentinitos, piroxenitos, tremolititos e gabros. A cava minerada possui 100 metros de extensão na direção NNE com espessura estimada entre 2,5 e 3 metros.

A mineralogia hidrotermal observada é composta por quartzo+clorita magnesiana+magnetita e as fases sulfetadas são compostas pelas associações pirita+calcopirita e pirita+covelita (Figuras 6A e 6B).

Seguindo o lineamento estrutural, a cerca de 100 metros na direção sul da cava minerada está localizado o afloramento aqui descrito. $\mathrm{O}$ contexto geológico é semelhante ao do garimpo, em que uma zona de falha intercepta os quartzitos da Formação Cruz das Almas e o cloritito. Este último possui espessura entre 1,5 e 2 metros, está milonitizado, com vênulas de quartzo subparalelas à foliação. Nesta nova tipologia, a mineralização aurífera está associada a um veio com 40 centímetros de espessura de pirita maciça com algum quartzo fumê associado ( $\mathrm{Fi}$ guras 7A e 7B).

\section{ANÁLISES QUÍMICAS}

O método utilizado para análise das amostras de rocha do garimpo Mina Velha e do veio de pirita maciça foi fusão por fire assay de amostras com massa maior que $0,5 \mathrm{~kg}$ e leitura dos elementos ouro, platina e paládio por ICP-AES (Inductively Coupled Plasma Atomic Emission Spectroscopy) com limite inferior de detecção igual a cinco ppb. No garimpo Mina Velha foram coletadas oito amostras no cloritito ao longo dos 100 metros de extensão da cava (Tabela 1). Os valores situaram-se entre 69 e 2901 ppb com destaque para as amostras HHI-271 e HHI-272. Os teores de Pd situam-se entre 8 e $31 \mathrm{ppb}$, enquanto para a platina a quase totalidade das amostras ficou abaixo do limite de detecção.

Ainda na cava da Mina Velha (Figura 8), veio de quartzo com pirita retornou valores entre $148 \mathrm{e}$ 22660 ppb de Au e entre 41 e 70 ppb de Pd. A borda ferruginosa que ocorre no contato entre o veio com pirita e o cloritito encaixante retornou valores de 161 e 166 ppb de Au e 179 e 212 ppb de Pd. As amostras do cloritito encaixante do veio retornaram 239 e 357 ppb de Au e 63 e 113 ppb de Pd. Para todas as amostras os valores para platina estão abaixo do limite de detecção (Tabela 2).

Na ocorrência de pirita maciça os valores encontrados para ouro foram de 336 e 385 ppb. As leituras para platina e paládio ficaram abaixo do limite de detecção (Tabela 2)

\section{DISCUSSÕES E CONCLUSÕES}

A mineralização aurífera associada a veios de pirita maciça constatada no presente estudo não é difundida na literatura sobre a região da Serra de Jacobina. A descrição mais próxima deste tipo de mineralização é feita por Silveira e Conceição Filho (1991) no garimpo Mina Velha, que relatam melhores teores de ouro associados às "venulações de quartzo com grandes concentrações de sulfetos". Desta forma, objetiva-se a divulgação desta tipologia de mineralização encontrada no Grupo Jacobina.

As características desta ocorrência permitem as seguintes conclusões:

i) o veio de pirita maciça mineralizado está hospedado em cloritito de direção N-S. Não é possível fazer uma correlação deste litotipo às unidades Greenstone Belt de Mundo Novo ou Complexo Itapicuru;

ii) A relação de contato observada indica que o cloritito está intrudido no quartzito da Formação Cruz das Almas do Grupo Jacobina. Pode-se inferir a ocorrência de um magmatismo máfico a ultramáfico posterior à deposição dos sedimentos do Grupo Jacobina;

iii) A rocha ultramáfica que hospeda o veio de pirita maciça é afetada por uma falha reversa com vergência para oeste e faz parte do mesmo trend estrutural do garimpo Mina Velha.

Este controle estrutural indica uma possível relação genética entre as mineralizações do garimpo e do veio de pirita maciça;

iv) A mineralogia hidrotermal, composta de sulfetos de ferro e cobre (pirita+calcopirita) e mag- 

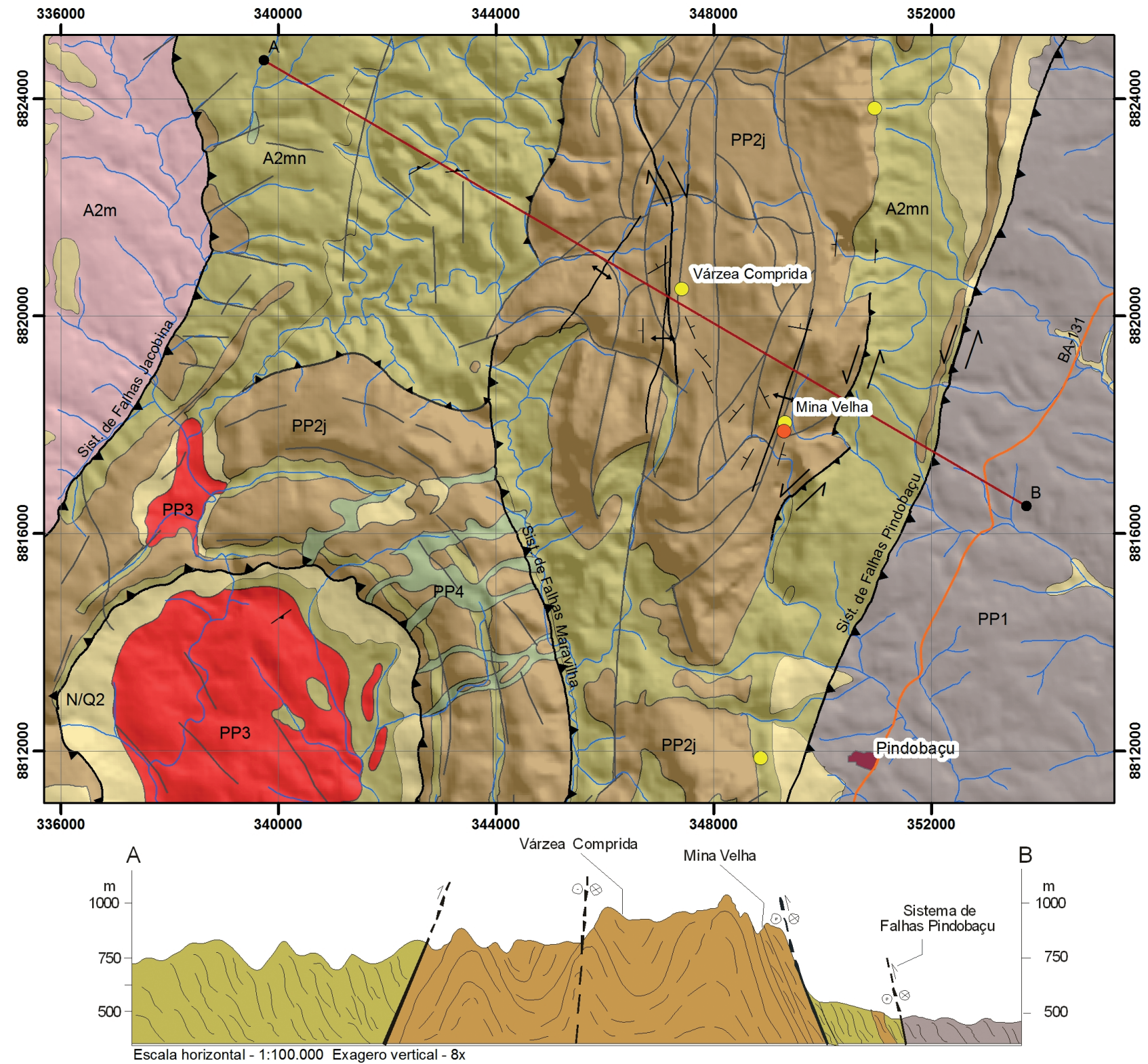

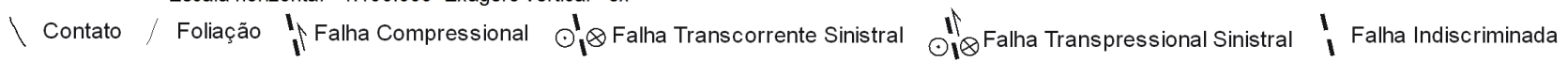

\begin{tabular}{|c|c|c|c|c|}
\hline ÉON & ERA & $\begin{array}{c}\mathrm{IDADE} \\
(\mathrm{Ma})\end{array}$ & \multicolumn{2}{|c|}{ COMPARTIMENTAÇÃO ESTRATIGRÁFICA } \\
\hline \multirow{2}{*}{ 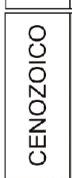 } & $\stackrel{\circ}{\stackrel{1}{C}}$ & \multirow{3}{*}{$\begin{array}{l}2.588 \\
1600\end{array}$} & \multicolumn{2}{|c|}{$\begin{array}{c}\text { FORMAÇÕES SUPERFICIAIS } \\
\text { CONTINENTAIS }\end{array}$} \\
\hline & 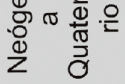 & & $N / Q 2$ & $\begin{array}{l}\text { Depósitos aluvionais, coluviais, } \\
\text { detrito-lateriticos. }\end{array}$ \\
\hline \multirow{5}{*}{ 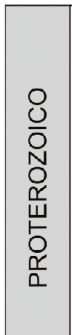 } & \multirow{5}{*}{$\begin{array}{l}\frac{0}{0} \\
\frac{.0}{0} \\
\frac{0}{0} \\
\frac{0}{0} \\
\frac{0}{0} \\
\frac{0}{0} \\
0\end{array}$} & & \multicolumn{2}{|r|}{ BLOCO GAVIÃO-LENÇÓIS } \\
\hline & & \multirow[b]{5}{*}{2500} & PP4 & Rochas gabroicas \\
\hline & & & PP3 & Granitogênese Orosiriana \\
\hline & & & PP2j & Grupo Jacobina \\
\hline & & & PP1 & Complexo Saúde \\
\hline & & & & \\
\hline \multirow{3}{*}{ 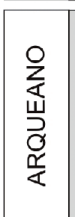 } & \multirow{3}{*}{ 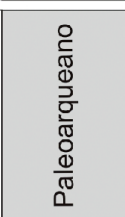 } & 3200 & \multicolumn{2}{|r|}{ BLOCO GAVIÃO-LENÇÓIS } \\
\hline & & & $\mathrm{A} 2 \mathrm{mn}$ & Greenstone Belt de Mundo Novo \\
\hline & & & $\mathrm{A} 2 \mathrm{~m}$ & Complexo Mairi \\
\hline
\end{tabular}

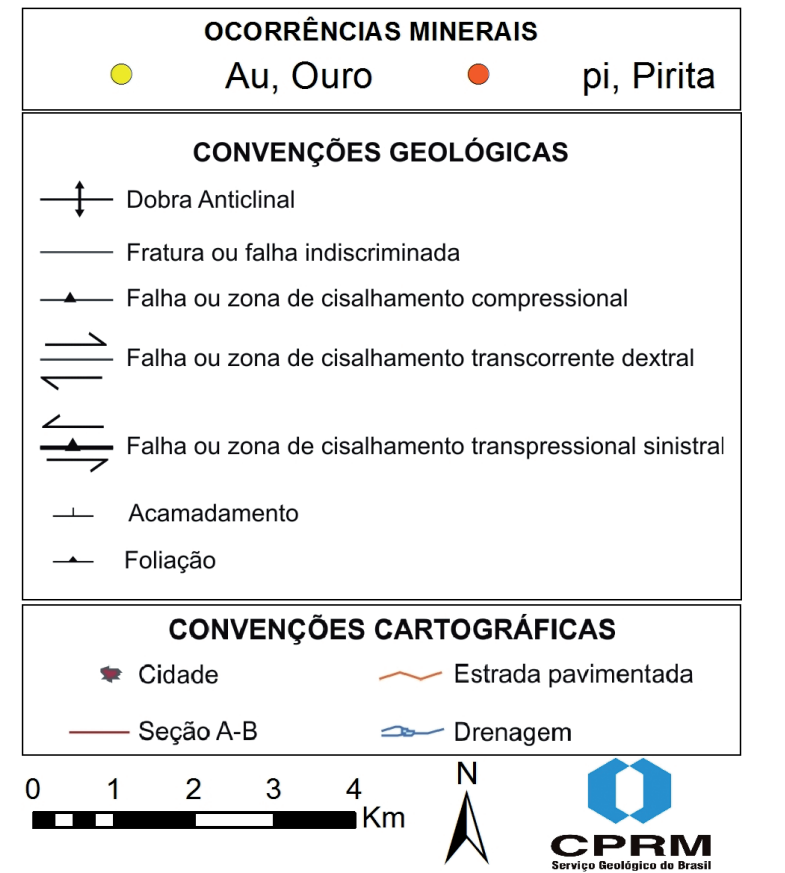

Figura 2 - Mapa geológico e seção geológica da região da Serra da Paciência. 


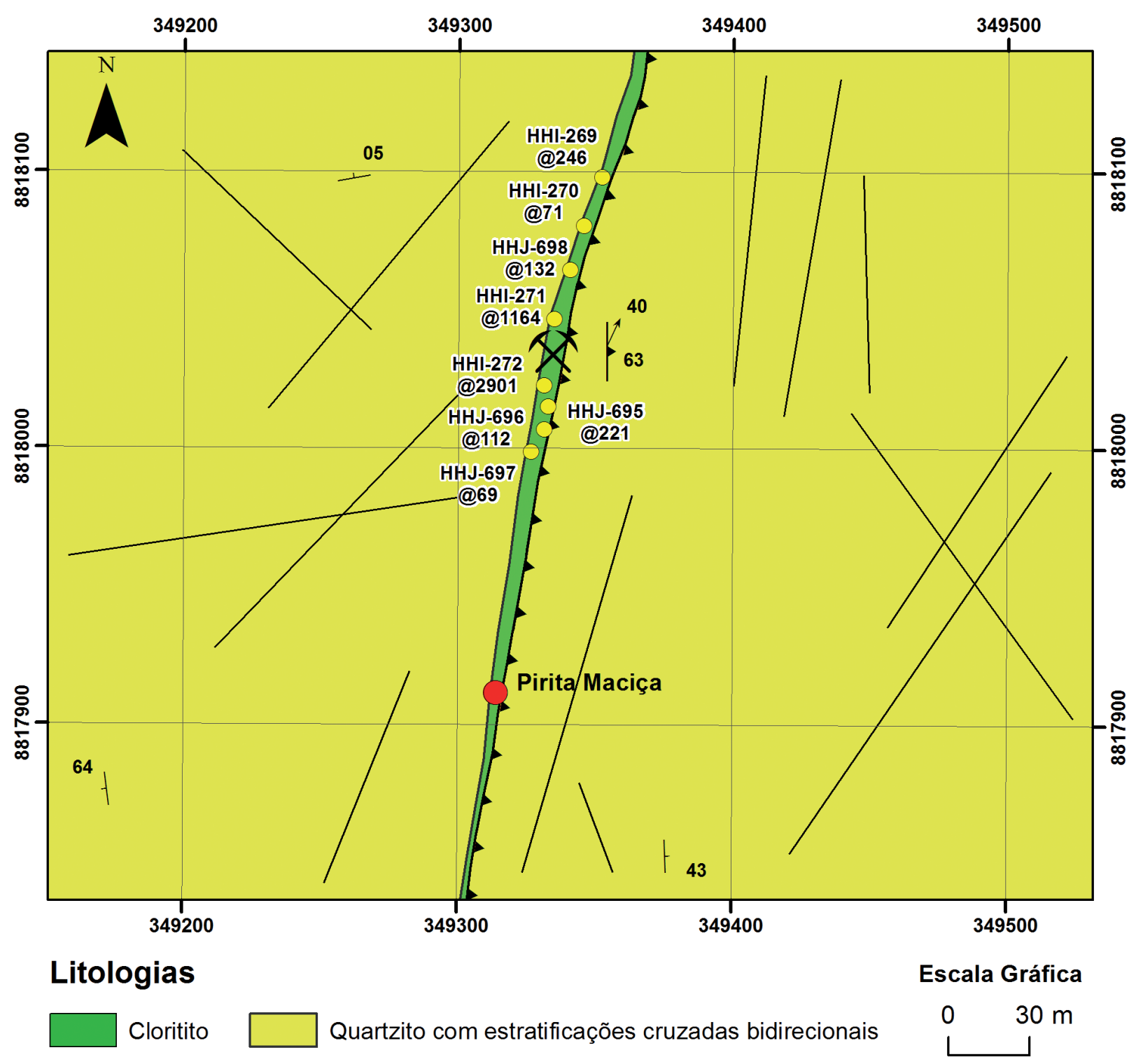

\section{Convenções}
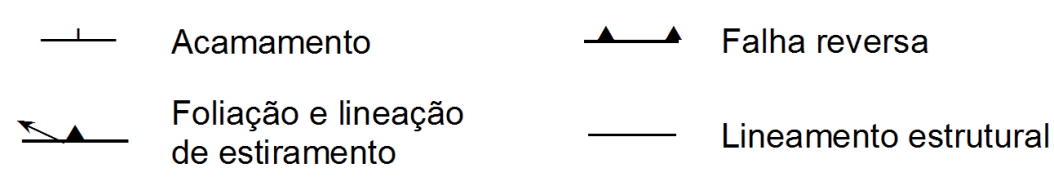

Х Garimpo Mina Velha

Número da Amostra

@teor Au(ppb)

Figura 3 - Esboço geológico do garimpo Mina Velha e entorno.

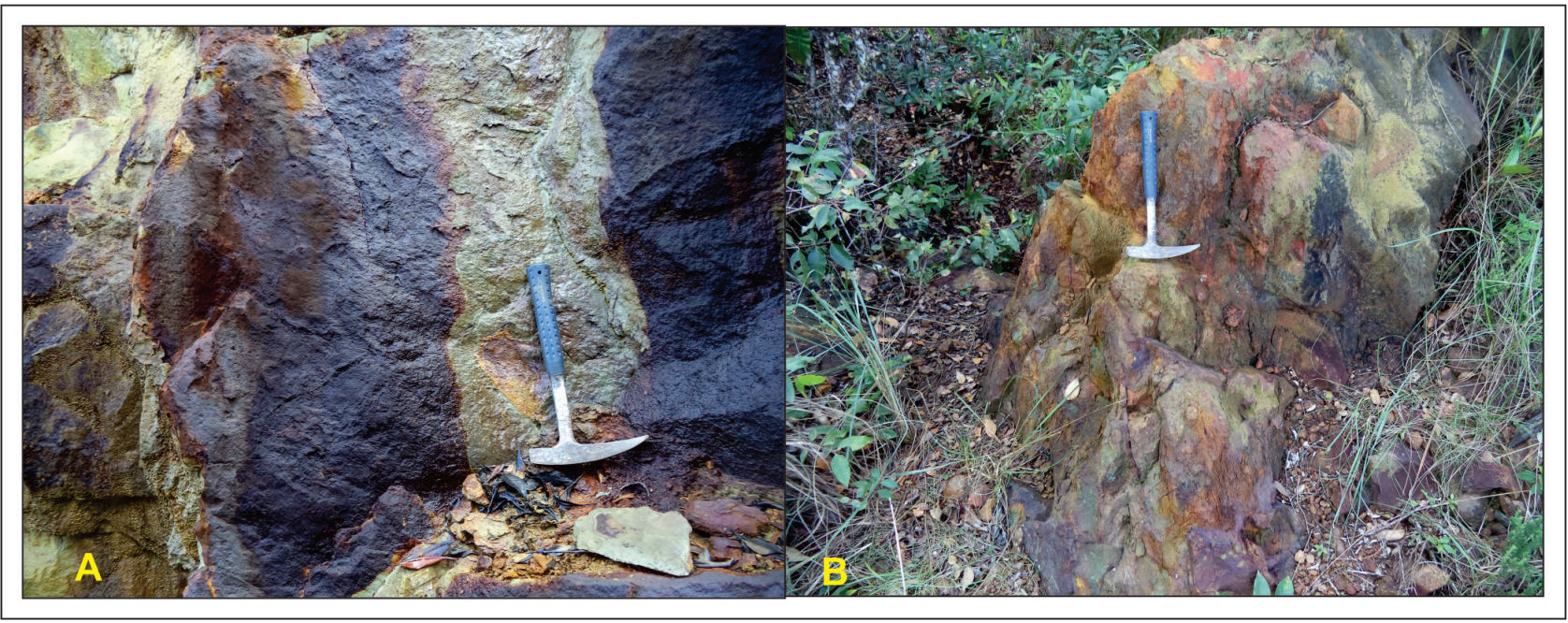

Figura 4 - A) Plano de falha hospedeiro da mineralização, atitude 095/63, lineação de estiramento 034/40.

B) Afloramento do cloritito. 


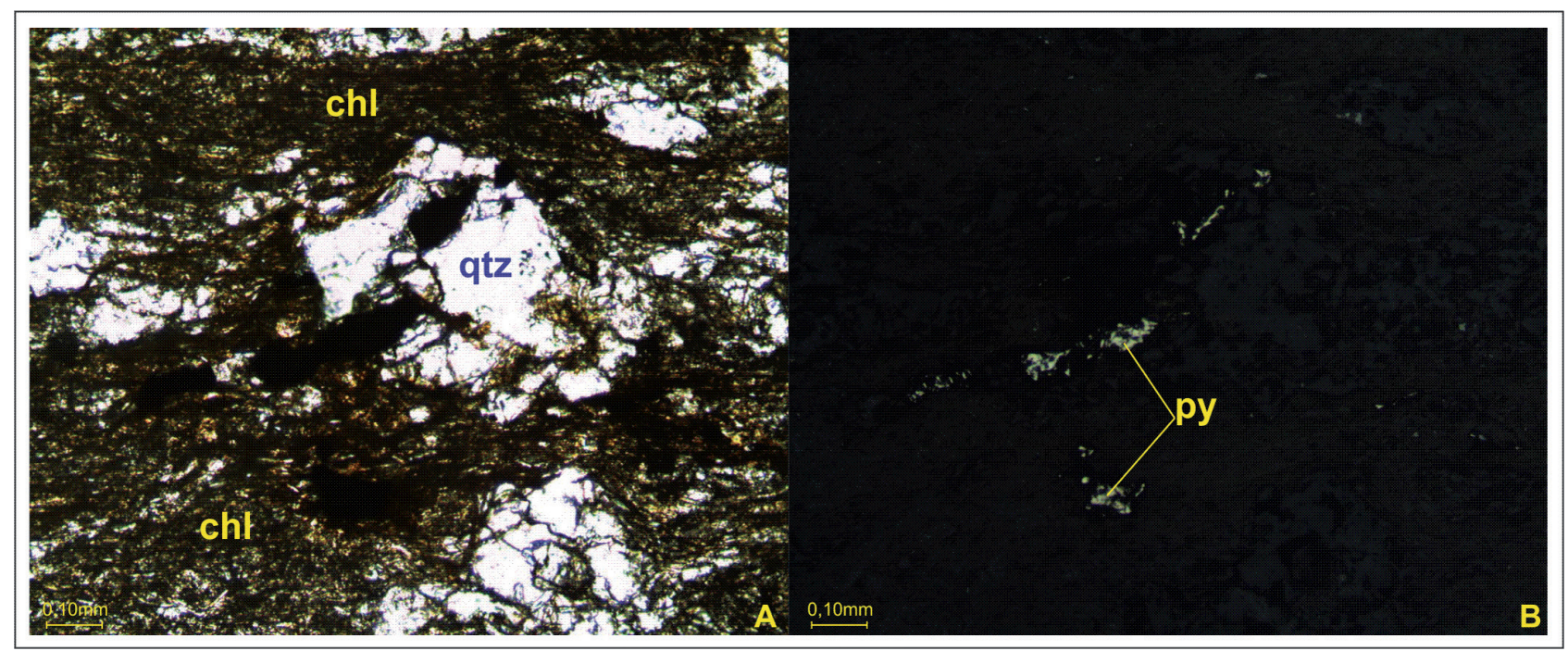

Figura 5 - A) Matriz essencialmente clorita (chl). Nicóis paralelos, aumento 10x. B) Cristais de pirita (py) orientados segundo a foliação e associados ao quartzo (qtz). Luz refletida, aumento 10x.

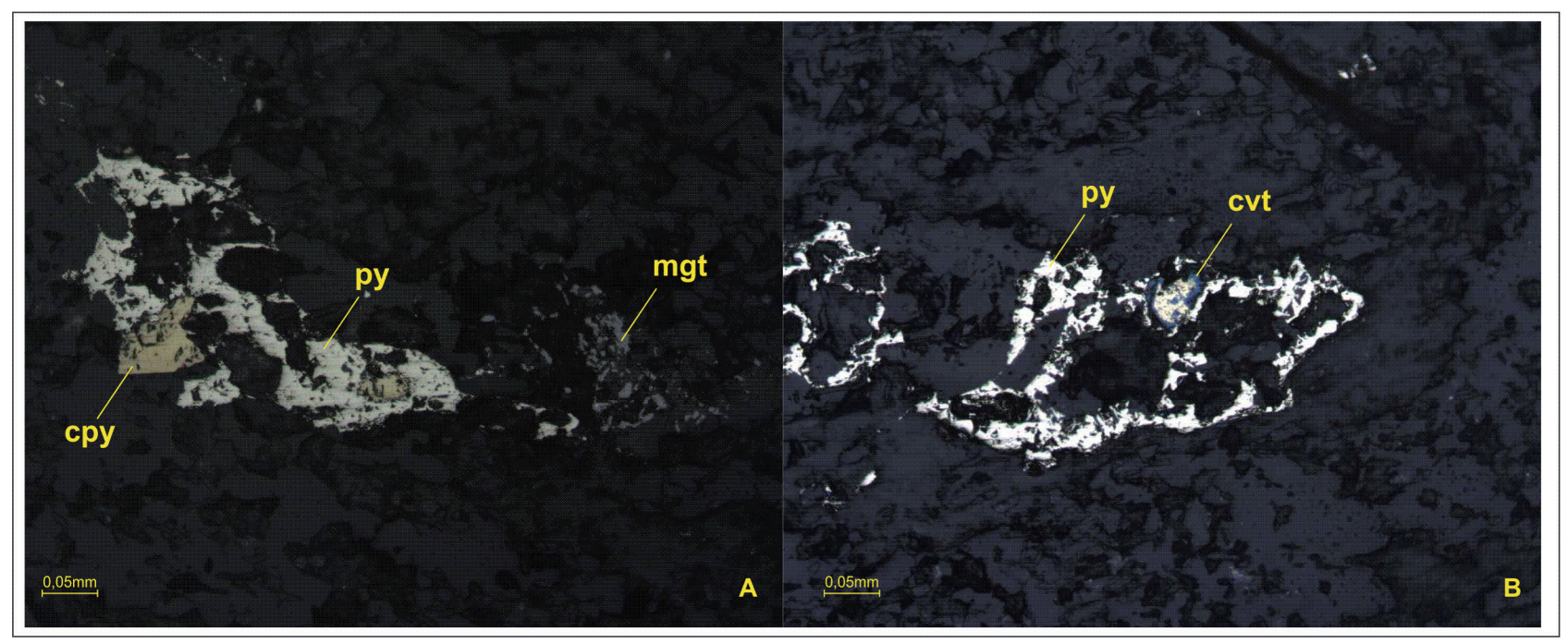

Figura 6 - A) Associação pirita+calcopirita+magnetita (py+cpy+mgt). Luz refletida, aumento 20x. B) Associação pirita+covelita (py+cvt). Luz refletida, aumento 20x.

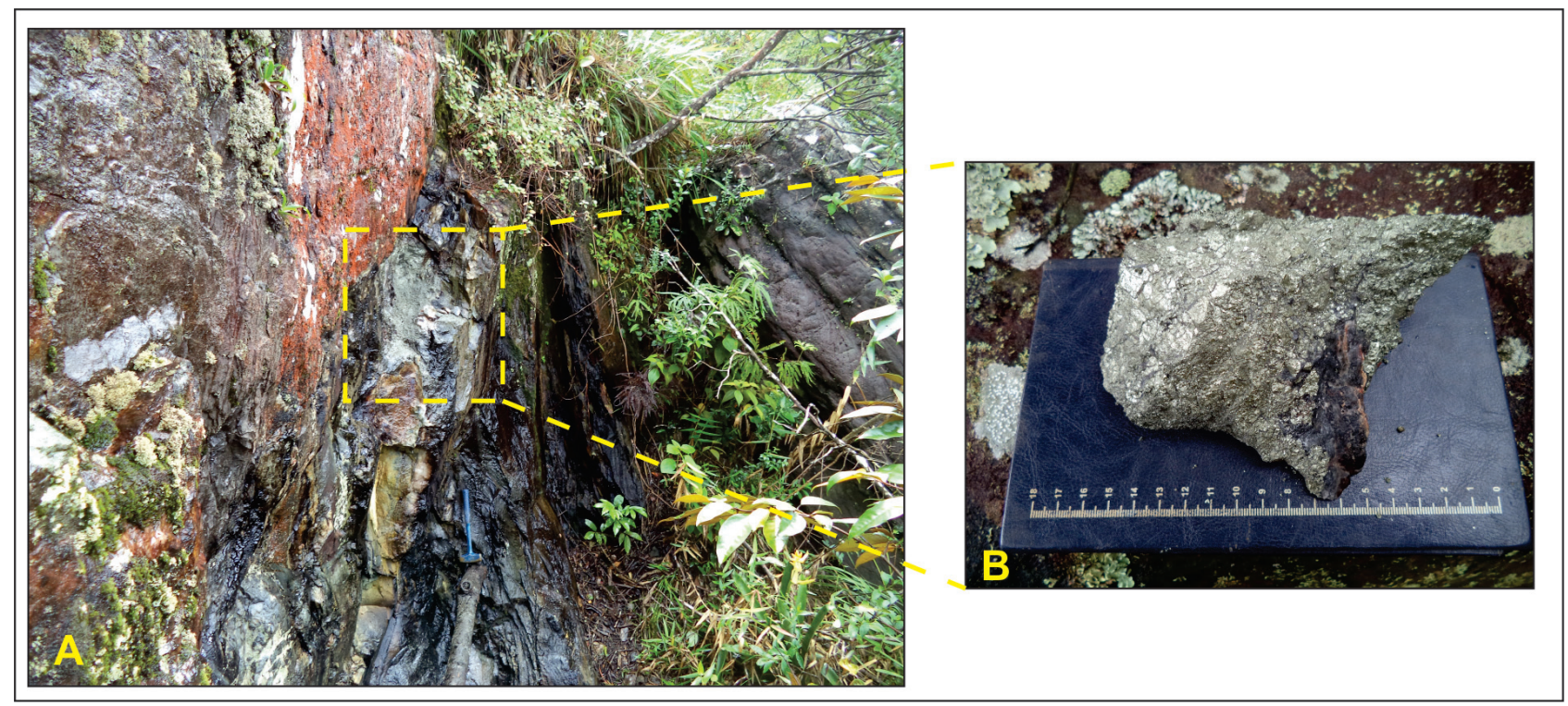

Figura 7 - A) visão geral da zona de falha e localização da amostra HHI-267 mostrada em 7 B. 
Tabela 1 - Resultados da análise do cloritito explorado pelos garimpeiros.

\begin{tabular}{|c|c|c|c|}
\hline Amostra & Au (ppb) & Pd (ppb) & Pt (ppb) \\
\hline HHI-269 & 246 & 26 & $<5$ \\
\hline HHI-270 & 71 & 8 & $<5$ \\
\hline HHI-271 & 1164 & 15 & $<5$ \\
\hline HHI-272 & 2901 & 16 & 11 \\
\hline HHI-695 & 221 & 18 & $<5$ \\
\hline HHI-696 & 112 & 18 & 6 \\
\hline HHI-697 & 69 & 16 & $<5$ \\
\hline HHI-698 & 132 & 31 & $<5$ \\
\hline
\end{tabular}

Tabela 2 - Resultado de análises químicas de rocha no garimpo Mina Velha e veio de pirita maciça.

\begin{tabular}{|c|c|c|c|c|c|}
\hline Amostra & Sítio Amostrado & Rocha & Au (ppb) & Pd (ppb) & Pt (ppb) \\
\hline HHJ-689 & Mina Velha & Veio com pirita & 283 & 41 & $<5$ \\
\hline HHJ-690 & Mina Velha & Veio com pirita & 148 & 70 & $<5$ \\
\hline HHJ-693 & Mina Velha & Veio com pirita & 22660 & 46 & $<5$ \\
\hline HHJ-694 & Mina Velha & Veio com pirita & 15920 & 41 & $<5$ \\
\hline HHJ-691 & Mina Velha & Borda ferruginosa & 166 & 212 & $<5$ \\
\hline HHJ-692 & Mina Velha & Borda ferruginosa & 161 & 179 & $<5$ \\
\hline HHJ-687 & Mina Velha & Cloritito & 357 & 113 & $<5$ \\
\hline HHJ-688 & Mina Velha & Cloritito & 239 & 63 & $<5$ \\
\hline HHI-267 & Mina Velha - veio extensão sul & Sulfeto maciço & 336 & $<5$ & $<5$ \\
\hline HHI-268 & Mina Velha - veio extensão sul & Sulfeto maciço & 385 & $<5$ & $<5$ \\
\hline
\end{tabular}
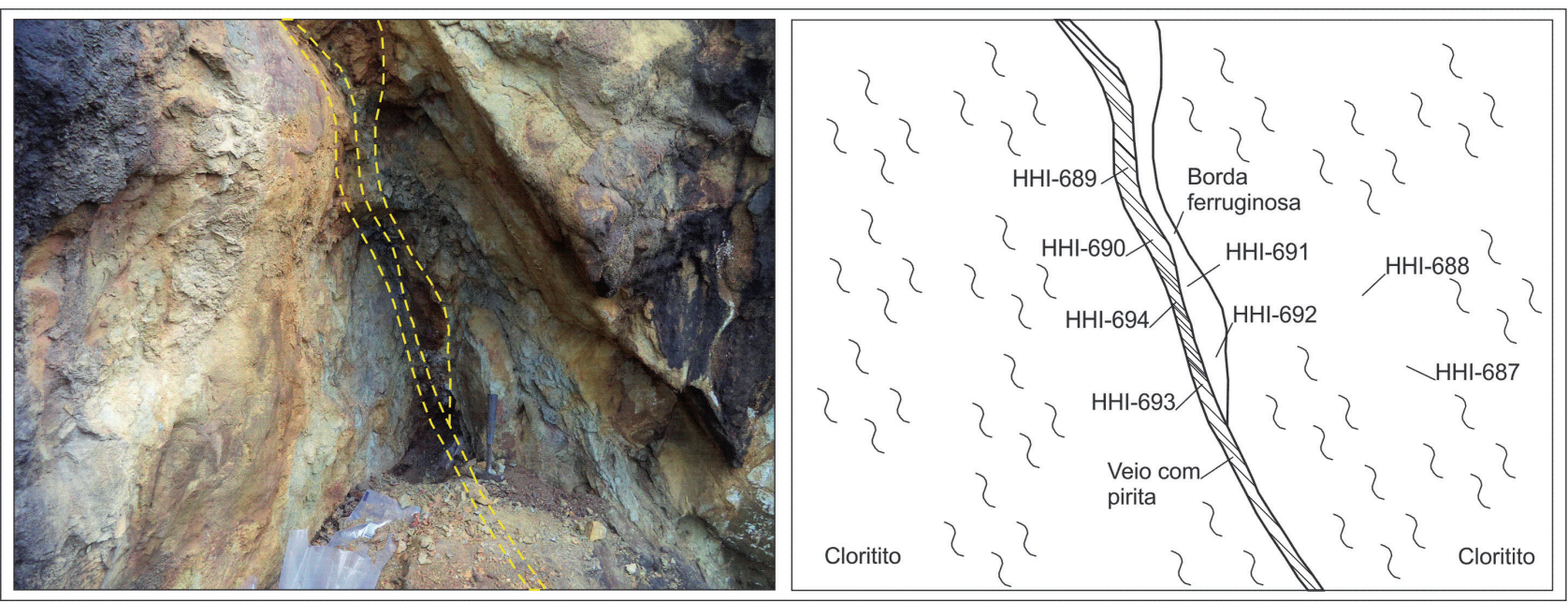

Figura 8 - Croqui de amostragem indicando a posição das amostras da Tabela 2.

netita, associada ao controle estrutural realizado pela falha reversa, sugere que a mineralização aurífera na pirita maciça pode ser oriunda da interação de fluidos hidrotermais canalizados tectonicamente e colocados em contato com as intrusões máficas a ultramáficas.

No garimpo Mina Velha é possível interpretar um zoneamento na mineralização aurífera, cujo núcleo rico em ouro é representado pelos veios de quartzo com pirita. Os teores diminuem em direção às bordas dos veios e se disseminam na encaixante ultramáfica. Teores de paládio associados à borda de alteração no contato entre os veios e o cloritito indicam potencial para mineralização deste elemento associado ao ouro.

Desta forma, a mineralização aurífera em veios de pirita maciça encaixada em diques de rochas ultramáficas, tectonicamente afetados pelos diversos falhamentos que ocorrem na Serra de Jacobina, se mostra como uma alternativa para exploração mineral diferente daquela dos conglomerados auríferos Serra do Córrego exaustivamente prospectados naquela região. 


\section{REFERÊNCIAS}

BATEMAN, J.D. Uranium-bearing auriferous reefs at Jacobina, Brazil. Economic Geology, v.54, p.417-425, 1958.

COUTO, P.A. et al. Projeto Serra de Jacobina: geologia e prospecção geoquímica. Relatório final. Texto. Salvador: CPRM, 1978. v.1. Convênio DNPM/CPRM.

COX, D.P. Regional environment of the Jacobina auriferous conglomerate, Brazil. Economic Geology, v.62, p.773-780, 1967.

GROSS, W.H. Evidence for a modified placer origin for auriferous conglomerates, Canavieiras Mine, Jacobina, Brazil. Economic Geology, v.63, p.271-276, 1968.

LEDRU, P. et al. Foreland basins and gold-bearing conglomerates: a new model for the Jacobina Basin (São Francisco Province, Brazil). Precambrian Research, v.86, p.155-176, 1997.

LEITE, C.M.M.; MARINHO, M.M. Serra de Jacobina e Contendas-Mirante. In: BARBOSA, J.S.F. (Coord.). Geologia da Bahia: pesquisa e atualização. Salvador: CBPM, 2012. v.1, p. 397-441.

MASCARENHAS, J.F.; SILVA, E.F.A. Greenstone Belt de Mundo Novo: caracterização e implicações metalogenéticas e geotectônicas no Cráton do São Francisco. Salvador: CBPM, 1994. (Série Arquivos Abertos, 5).
MASCARENHAS, J.F. et al. Geologia e recursos minerais do Grupo Jacobina e da parte sul do Greenstone Belt de Mundo Novo. Salvador: CBPM, 1998. (Série Arquivos Abertos, 13).

MILESI, J.P. et al. The Jacobina Paleoproterozoic gold-bearing conglomerates, Bahia, Brazil: a "hydrothermal shear-reservoir" model. Ore Geology Reviews, v.19, p.95-136, 2002.

PEARSON, W. et al. Geology and gold mineralization of the Jacobina Mine and Bahia Gold Belt, Bahia, Brazil and a comparison to Tarkwa and Witwatersrand. In: RHODEN, H.N.; STEININGER, R.C.; VIKRE, P.G. (Ed.). Geological Society of Nevada Symposium 2005. Reno, Nevada: GSN, 2005. p. 757-785.

SILVEIRA, W.P.; CONCEIÇÃO FILHO, V.M. Avaliação geológica do potencial aurífero do prospecto Vargem Comprida, Pindobaçu, Bahia. Salvador: CBPM, 1991. 18p. Relatório Interno.

TELES, G.; CHEMALE, F.; OLIVEIRA, C.G. Paleoarchean record of the detrital pyrite-bearing, Jacobina Au-U deposits, Bahia, Brazil. Precambrian Research, v.256, p.289-313, 2015.

TEIXEIRA, J.B.G. et al. Gold mineralization in the Serra de Jacobina region, Bahia Brazil: tectonic framework and metallogenesis. Mineralium Deposita, v.36, p.332-344, 2001.

WHITE, M.G. Origin of uranium and gold in the quartzite-conglomerate of the Serra de Jacobina. Washington: USGS, 1961. (Paper 424B, 9B).

\section{INFORME TÉCNICO $\mathbf{N}^{\circ} \mathbf{9}$ \\ Brasília, março de 2017. \\ ISSN: 2448-2242 \\ Publicação on-line seriada \\ CPRM - Serviço Geológico do Brasil. \\ Disponível em: www.cprm.gov.br}

CPRM - Serviço Geológico do Brasil

SBN - Quadra 02 - Bloco H, Ed. Central Brasília, $1^{\circ}$ andar Brasília - DF - Brasil

CEP: 70040-904

Telefone:(61) 2108-8400

www.cprm.gov.br

contatos: seus@cprm.gov.br evandro.klein@cprm.gov.br

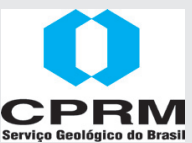

Diretor de Geologia e Recursos Minerais José Leonardo Silva Andriotti

\section{Corpo Editorial}

Evandro Luiz Klein (Editor)

Edilton José dos Santos

João Henrique Larizzatti

Luiz Gustavo Rodrigues Pinto

\section{Revisores}

Leandro Duarte Campos

Noevaldo Araújo Teixeira

Evandro Luiz Klein

\section{Normalização Bibliográfica}

Isabel Ângela dos Santos Matos

\section{Editoração Eletrônica}

Marcelo Henrique Borges Leão

Nelma Fabrícia da P. Ribeiro Botelho 